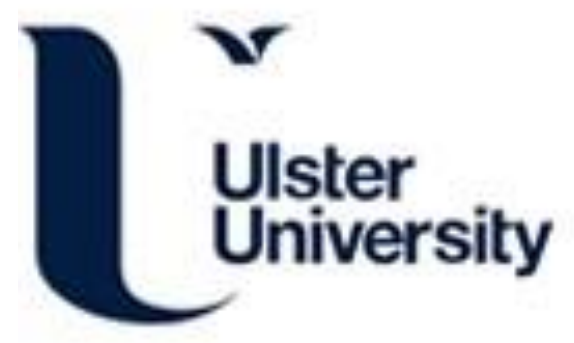

\title{
Thermal characterisation with modelling for a microgravity experiment into polycrystalline equiaxed dendritic solidification with in-situ observation
}

Mooney, R. P., Sturz, L., Zimmermann, G., \& McFadden, S. (2018). Thermal characterisation with modelling for a microgravity experiment into polycrystalline equiaxed dendritic solidification with in-situ observation. International Journal of Thermal Sciences, 125, 283-292. https://doi.org/10.1016/J.IJTHERMALSCI.2017.11.032

Link to publication record in Ulster University Research Portal

Published in:

International Journal of Thermal Sciences

Publication Status:

Published (in print/issue): 31/03/2018

DOI:

10.1016/J.IJTHERMALSCI.2017.11.032

\section{Document Version}

Author Accepted version

\section{General rights}

Copyright for the publications made accessible via Ulster University's Research Portal is retained by the author(s) and / or other copyright owners and it is a condition of accessing these publications that users recognise and abide by the legal requirements associated with these rights.

\section{Take down policy}

The Research Portal is Ulster University's institutional repository that provides access to Ulster's research outputs. Every effort has been made to ensure that content in the Research Portal does not infringe any person's rights, or applicable UK laws. If you discover content in the Research Portal that you believe breaches copyright or violates any law, please contact pure-support@ulster.ac.uk. 


\title{
Thermal characterisation with modelling for a microgravity experiment into polycrystalline equiaxed dendritic solidification with in-situ observation
}

\author{
Robin P. Mooney ${ }^{1}$, Laszlo Sturz ${ }^{2}$, Gerhard Zimmermann², Shaun McFadden ${ }^{1,3}$ \\ ${ }^{1}$ Dept. of Mechanical \& Manufacturing Engineering, Trinity College Dublin, D2, Ireland. \\ ${ }^{2}$ ACCESS e.V., Intzestrasse 5, 52072 Aachen, Germany. \\ ${ }^{3}$ School of Computing, Engineering and Intelligent Systems, Ulster University, BT48 7JL \\ Northern Ireland, United Kingdom.
}

Corresponding author: $\underline{\text { s.mcfadden2@ulster.ac.uk }}$

\begin{abstract}
The Multiple Equiaxed Dendrite Interaction (MEDI) experiment was launched on the MASER13 sounding rocket campaign to investigate polycrystalline equiaxed solidification in the transparent phase change material Neopentylgycol-30wt.\%(d)Camphor. This material is of interest as an energy-storage material and as a transparent analogue system of solidification in hypoeutectic metal alloys with a Face Centred Cubic lattice. The liquid sample was cooled under a controlled rate of $0.75 \mathrm{~K} / \mathrm{min}$ with sufficient time to allow semi-solid conditions to develop under microgravity conditions with the absence of gravity-driven convection. This manuscript provides details on the experimental apparatus and procedures. In addition, the experimental method has been augmented with a numerical model to assist with the characterisation of the essential thermal aspects of the experiment. The model followed a volume-averaging, continuum approach for mushy-zone development. A fast algorithm for computing non-isothermal crystallisation kinetics was applied to the case of binary alloy solidification. To build confidence, a formal numerical verification procedure was performed. The model converged sufficiently with second order accuracy as expected. Application of the model gave close agreement between experimental thermocouple readings and numerical simulation data with a Root Mean Square of $0.2 \mathrm{~K}$ for the error. A 2D thermal model is sufficient with a suitable heat loss coefficient at the sample-viewing window boundary. Thermal gradients within the sample and along the growth direction were uniform and approximately $0.3 \mathrm{~K} / \mathrm{mm}$. Lateral thermal gradients in the sample ranged from zero at the median plane to $0.3 \mathrm{~K} / \mathrm{mm}$ at the boundary with the containing structure. However, temperature variation in the lateral direction was predicted to be less than $0.22 \mathrm{~K}$.
\end{abstract}

\section{Keywords}

Model development; equiaxed solidification; microgravity; transparent analogue alloy; 


\section{Introduction}

Under microgravity conditions, the complicating effects of gravity-driven convection and buoyancy in a liquid phase are supressed significantly. Hence, microgravity experiments are used to study solidification phenomena under diffusive conditions. Recent examples include dendritic growth in metallic alloys [1][2] and solidification in a transparent alloy [3]. Results from microgravity experiments (and the associated modelling work) provide fundamental benchmark data that can be compared to experimental data and model outputs where gravitydriven convection is included [4][5]. Hence, the effects of convection on the solidifying structure can be clearly understood.

The Columnar-to-Equiaxed Transition in SOLidification Processing (CETSOL) programme [6][7][8] is an example of a European Space Agency (ESA) Microgravity Application Promotion (MAP) that applies various microgravity platforms to study physical phenomenon. A CETSOL microgravity sounding rocket campaign, called the Multiple Equiaxed Dendrite Interaction (MEDI) experiment, was launched on December $1^{\text {st }} 2015$ from Esrange, Sweden. The MEDI experiment was part of the MASER-13 campaign. The objectives of MEDI were to examine equiaxed dendritic nucleation, growth, interaction, and impingement in a transparent hypoeutectic alloy system, Neopentylglycol30wt.\%(d)Camphor. Observations of equiaxed dendritic solidification were made in-situ and in real-time using optical methods at macro and micro length scales.

Any microgravity experiment that is designed to investigate solidification processes for a given alloy system will benefit from the application of dedicated thermal model. However, the details of any thermal characterisation procedures-the process of applying a suitable thermal model and appropriate boundary conditions-need to be demonstrated. The risk, due to the significant challenges posed, is that boundary conditions may be assumed without detailed quantitative analysis.

This contribution provides detail on the development and application of a numerical thermal model for the MEDI experiment and the thermal characterisation procedures used to determine appropriate boundary conditions. Thermocouple (TC) data from the experiment were compared with the model output and good agreement is demonstrated. The model provides, with confidence, a description of the thermal conditions experienced in the MEDI microgravity experiment on board the MASER-13 campaign. 


\subsection{Aims and objectives}

The formal aims and objectives for this investigation are set out as follows:

(1) Describe the MEDI experimental set-up and procedures.

(2) Develop an appropriate thermal model of the experiment.

(3) Provide confidence in the model's numerical scheme and results.

(4) Provide an assessment of the thermal conditions experienced during the experiment.

Section 2 of this manuscript, Experimental materials and methods, expands upon the first aim. Sections 3 describes the thermal model selected for the analysis and the process of determining the boundary conditions. Section 4 provides results-both experimental and simulation results with some explanations and preliminary discussion. Section 5 provides detailed discussion on the findings of the thermal characterisation. Section 6 , the conclusion section, summarises the outcomes from this manuscript in the context of the stated aims and objectives.

\section{Experimental materials and methods}

\section{$2.1 \quad$ Neopentylglycol-(d)camphor alloy}

Neopentylglycol-30wt.\%(d)Camphor is a hypoeutetic alloy with a well-defined phase diagram [9]. It is of interest as energy storage material and as an analogue to metal alloy solidification. In the liquid phase, the alloy is transparent at visible wavelengths; however, the solid phase has higher opacity to visible light. The solidifying dendritic solid can be clearly distinguished from the liquid. Significant experience had been developed with a similar alloy (with a composition of 37.5wt.\%(d)Camphor) on board the TRACE microgravity campaign $[3,10]$. Table 1 provides thermophysical properties for the alloy. The raw materials Neopentylglycol (NPG) and (d)Camphor were purified by sublimation, alloyed under Argon atmosphere and delivered in glass syringes for filling into an evacuated experimental cell chamber.

Table 1 Thermophysical properties for Neopentyglycol-30\%wt.-(d)Camphor.

\begin{tabular}{lccrc}
\hline Property & Symbol & Value & Units & Ref \\
\hline Thermal conductivity of liquid & $k_{l}$ & 0.12 & {$[\mathrm{~W} / \mathrm{mK}]$} & {$[11]$} \\
Thermal conductivity of solid & $k_{s}$ & 0.27 & {$[\mathrm{~W} / \mathrm{mK}]$} & {$[11]$} \\
Density of liquid or solid & $\rho$ & 960 & {$\left[\mathrm{~kg} / \mathrm{m}^{3}\right]$} & \\
Specific heat capacity of liquid & $c_{p(l)}$ & $211[\mathrm{~J} / \mathrm{kgK}]+6.4\left[\mathrm{~J} / \mathrm{kgK}^{2}\right] T$ & {$[9]$} \\
\hline
\end{tabular}




\begin{tabular}{lccrc}
\hline Specific heat capacity of solid & $c_{p(s)}$ & $940[\mathrm{~J} / \mathrm{kgK}]+4.2\left[\mathrm{~J} / \mathrm{kgK}^{2}\right] T$ & {$[9]$} \\
Latent heat of fusion per unit mass & $L$ & 23900 & {$[\mathrm{~J} / \mathrm{kg}]$} & {$[9]$} \\
Equilibrium liquidus temperature & $T_{L}$ & 352.45 & {$[\mathrm{~K}]$} & {$[9]$} \\
Equilibrium eutectic temperature & $T_{E}$ & 326.05 & {$[\mathrm{~K}]$} & {$[9]$} \\
Melting temperature of pure NPG & $T_{M}$ & 404.71 & {$[\mathrm{~K}]$} & {$[9]$} \\
Partition coefficient & $k_{\text {part }}$ & 0.072 & {$[-]$} & {$[9]$} \\
Diffusivity of solute in liquid & $D_{l}$ & 97 & {$\left[\mu \mathrm{m}^{2} / \mathrm{s}\right]$} & {$[9]$} \\
\hline
\end{tabular}

\subsection{Experiment apparatus}

Airbus Defence \& Space designed, built, and provided operational support on the MEDI experimental module. Figure 1 shows the experimental cell and reference coordinate system. Figure 2 shows a schematic for the thermal control system for the cell.
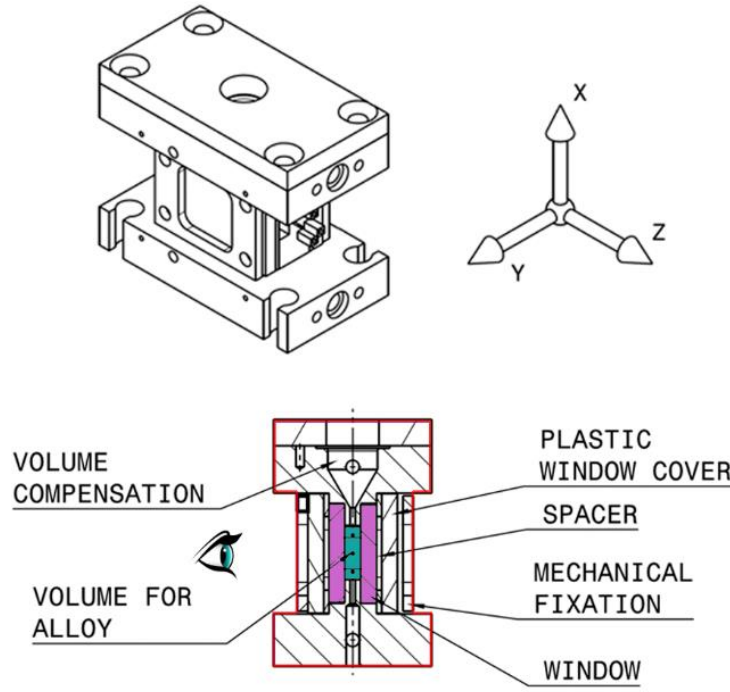

Figure 1 MEDI experiment cell.

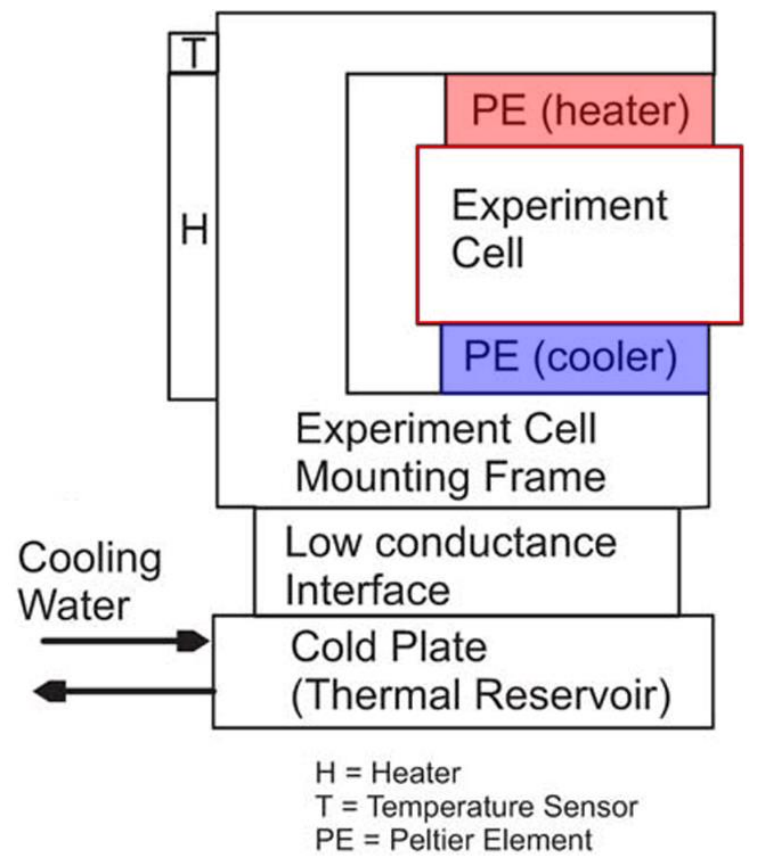

Figure 2 MEDI experiment module.

The cell volume for containing the alloy (the central volume in Figure 1) had nominal dimensions of $10 \mathrm{~mm}$ high $(H), 13 \mathrm{~mm}$ wide $(W)$, and $3 \mathrm{~mm}$ deep $(D)$. A heated volume compensation reservoir was located in the top of the cell to deal with material expansion and shrinkage.

Peltier Element devices (PE in Figure 2) were employed at the top and bottom of the cell to control the temperatures so that a temperature gradient in the $x$-direction could be established. The PE devices had thermocouples embedded within their structure to permit temperature control at each device location. However, it should be noted that these thermocouples had insufficient proximity to the boundary of the experimental cell to be considered as boundary conditions for the cell volume. 
Three Ni-CrNi TCs with diameter $0.25 \mathrm{~mm}$ were located in the $x-z$ median plane of the cell (see Figure 3) and were directly in contact with the alloy material. The TCs were located at heights $1.4 \mathrm{~mm}, 4.9 \mathrm{~mm}$, and $8.2 \mathrm{~mm}$ relative to the bottom of the cell (i.e., the position selected as the experimental datum position: $x=0 \mathrm{~mm}$ ).

Solidification of the alloy was observed through a backlit quartz glass window, covered by acrylic glass on either side (parallel to the $x$-z median plane). Digital images were recorded and stored on-board while an analogue video stream was used for experimental control on ground.

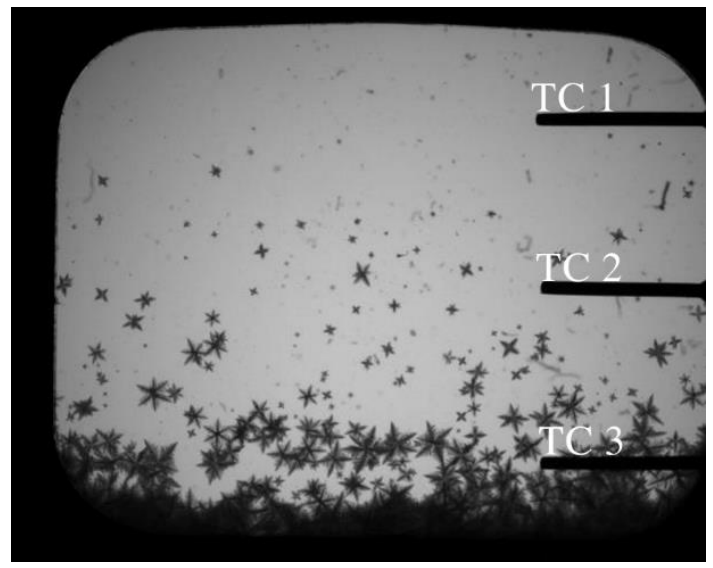

Figure 3 Overview image.

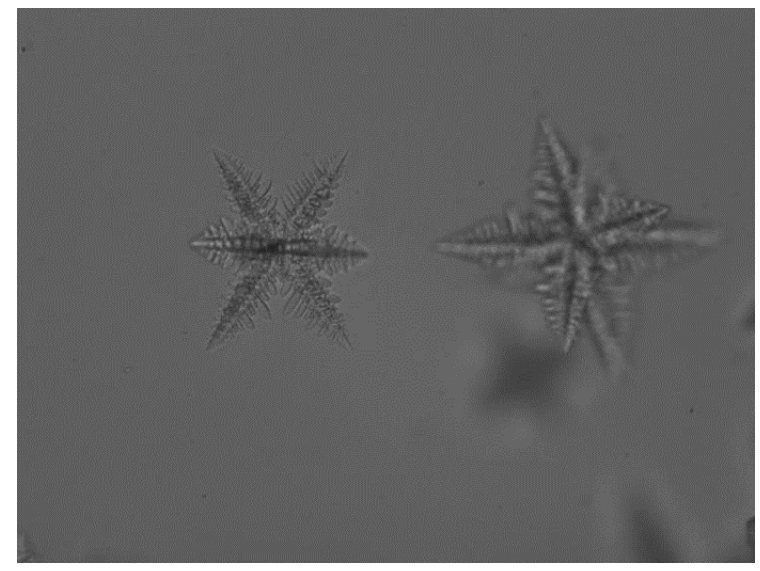

Figure 4 Detail view image.

Two optical systems were employed: one to obtain a macroscopic view of the entire window; the other to obtain a microscopic view of individual dendritic crystals. For the macroscopic view, an overview digital image was captured (Figure 3) with a field of view (FoV) $13.6 \mathrm{~mm}$ wide by $10.9 \mathrm{~mm}$ high $(1280 \times 1024$ pixels in size, giving an optical resolution of $10.625 \mu \mathrm{m} /$ pixel). Images were recorded in 8-bit grayscale and at 10 frames per second. The depth of field was sufficient to include the full thickness of the sample $(3 \mathrm{~mm})$.

In the microscopic view, detailed digital images were obtained (see Figure 4 for an example) using microscope optics with a FoV $1.44-\mathrm{mm}$ wide by $1.08-\mathrm{mm}$ high $(1600 \times 1200$ pixels in size); hence, giving an optical resolution of $0.9 \mu \mathrm{m} /$ pixel. These images were recorded in 8-bit grayscale and at 20 frames per second. In the detailed microscopic view, stacks of images were recorded to capture focused detail by automated scan in the $y$-direction with $6 \mu \mathrm{m}$ between each stack image. In both systems, camera parameters were optimised for brightness and contrast. 


\subsection{Experimental procedure}

The following steps were taken before lift-off (LO): the sample was melted by applying a temperature of approximately $353.15 \mathrm{~K}$ (above the equilibrium liquidus temperature, $T_{L}=352.45 \mathrm{~K}$ ) at the top and bottom of the experiment cell. Natural convective mixing of the molten liquid was induced by temperature inversion (i.e., making the top slightly colder than the bottom). Next, a stable temperature gradient was set up in the $x$-direction by setting the bottom heater temperature to $349.15 \mathrm{~K}$ and the top heater to $355.15 \mathrm{~K}$. Sufficient time was provided for thermal equilibrium. At these settings, the entire sample volume was confirmed to be liquid. There were no observed nucleation events at this point in the experiment. With a starting time relative to $\mathrm{LO}$ of $-235 \mathrm{~s}$, the temperatures of the heaters were decreased simultaneously and in a controlled manner at a constant rate of $0.75 \mathrm{~K} / \mathrm{min}$. Thereafter, these thermal control settings were maintained during the rocket launch ( $\mathrm{LO}$ at $t=0 \mathrm{~s}$ ), motor separation, de-spinning of the payload, microgravity period and re-entry of the payload into the atmosphere. These control settings ensured that the first observed nucleation event occurred shortly after the start of the microgravity period, $t=169 \mathrm{~s}$. The microgravity period, relative to LO, was approximately 6 minutes, from $t=89 \mathrm{~s}$ to $t=468 \mathrm{~s}$.

\section{Modelling methodology}

This section describes the details of the mathematical model followed by details of the numerical implementation and verification procedure.

\subsection{Governing mathematical model}

\subsubsection{Heat equation and equiaxed model}

The general heat equation for a solidification process in the absence of convection [12][13] and volumetric radiation [14] is

$$
\frac{\partial\left(\rho c_{p} T\right)}{\partial t}=\nabla(k \nabla T)+\rho L \frac{\partial f_{s}}{\partial t}
$$

where $\rho$ is density, $c_{p}$ is specific heat capacity, $T$ is temperature, $t$ is time, $L$ is the latent heat per unit mass and $f_{s}$ is the volumetric solid fraction per control volume $\left(f_{s}=V_{s} / V_{C V}\right) . V_{s}$ is the volume of solid in a given control volume of size $V_{C V}$. The thermal conductivity is given as $k$. The second term on the right hand side accounts for the release of latent heat due to 
solidification. Hence, the governing equation used here is a transient model with coupling between sensible and latent heat terms.

The following specific form of the heat equation was deemed appropriate,

$$
\frac{\partial\left(\rho c_{p} T\right)}{\partial t}=\frac{\partial}{\partial x}\left(k \frac{\partial T}{\partial x}\right)+\frac{\partial}{\partial y}\left(k \frac{\partial T}{\partial y}\right)+\rho L g_{s} \frac{\partial \zeta_{V}}{\partial t}+\rho L \zeta_{V} \frac{\partial g_{s}}{\partial t}
$$

Heat flow is modelled in two directions, namely, $x$ and $y$ (Figure 1). The latent heat term has been expanded as two terms (a thickening term and an advancing term). The volumetric solid fraction within the mush is given by $g_{\mathrm{s}}$. The volumetric fraction of mush within the control volume is given as $\zeta_{V}$ (also described as the grain fraction). These fractions are described mathematically as follows,

$$
\begin{gathered}
g_{s}=\frac{V_{s}}{V_{m}}, \\
\zeta_{V}=\frac{V_{m}}{V_{C V}},
\end{gathered}
$$

where $V_{m}$ is the volume of mush. The solid fraction of a control volume, $f_{s}$, is a product of the local solid fraction within the mush and the volumetric fraction of the mush, that is, $f_{s}=g_{s} \zeta_{\mathrm{V}}$. The benefit of expanding the latent heat term as two separate terms is that the thickening and the growth kinetics are treated separately. The thickening term requires a micro-segregation description to relate solid fraction to temperature. The advancement term requires both nucleation and growth information.

The solid fraction within the mush, $g_{s}$, can be approximated based on the Scheil micro-segregation principle for a eutectic alloy as follows,

$$
g_{s}=\left\{\begin{array}{ccc}
1-\left(\frac{T_{M}-T}{T_{M}-T_{L}}\right)^{\frac{1}{k_{p a r t}-1}} & \forall & T_{E}<T<T_{L} \\
1-\frac{\mathrm{H}-\rho c_{p} T_{E}}{\rho L} & \forall & T=T_{E}
\end{array} .\right.
$$

$T_{M}$ is the melting point of the solvent, $T_{L}$ is the equilibrium liquidus temperature of the alloy, and $T_{E}$ is the equilibrium eutectic temperature of the alloy. The enthalpy is given as $\mathrm{H}$. This method assumes that the solute flux from within the grain envelope to the external liquid is negligible. McFadden and Browne [13] provide further details on the detailed implementation of this algorithm.

Rappaz and Thévoz $[15,16]$ provide an alternative method to estimate the fraction of solid 
within an equiaxed mushy envelope. Similar to the Scheil approach, Rappaz and Thévoz assumed complete mixing of solute in the inter-dendritic liquid and no back-diffusion in the solid. However, solute balance at the circumference of the spherical envelope was assumed; therefore, a solutal boundary layer around the envelope was modelled. An analytical solution [16] was developed where the solute field ahead of the equiaxed dendrite tip was linearized and solute flux outside of the envelope was considered to give an estimation of solid fraction inside the mush, as follows,

$$
g_{s}=\frac{c^{*}-c_{o}}{c^{*}\left(1-k_{\text {part }}\right)}\left[1+\frac{3}{2} Z+Z^{2}+\frac{Z^{3}}{4}\right] \text {. }
$$

where $c^{*}$ is the composition of liquid at the tip and $Z$ is the reciprocal of the grain Péclet number which is given by: $P e=v_{t i p} R_{g} / 2 D_{l}$, where $R_{g}$ is the grain radius and $D_{l}$ the diffusion coefficient of solute in the liquid. In the application of the Rappaz-Thévoz models, the initial conditions are such that initial growth is set to occur as a solid sphere $\left(g_{s}=1\right)$ but quickly proceeds to represent a mushy spherical envelope $\left(g_{s}<1\right)$.

In ref. [15], it was shown that when the diffusion layer thickness is small, then the solid fraction calculation approached a Scheil calculation. Diffusion boundary layer thickness is directly proportional to the diffusivity of solute in liquid. We should note that for the alloy of interest here the diffusivity of solute in liquid is two orders of magnitude lower than for a typical binary aluminium alloy. This value for diffusivity suggests that the solutal boundary layers should be small. Nevertheless, a direct comparison has been made using results from each approach, i.e., using equation (5) versus equation (6). Results from each method are shown in section 4 with discussion provided in section 5.2 .1 of this manuscript.

The fraction of mush, $\zeta_{V}$, is calculated using the well-established Johnson-MehlAvrami-Kolmogorov [17-21] (JMAK) equation as follows,

$$
\zeta_{V}=1-\exp \left(-\zeta_{V, E X}\right)
$$

where $\zeta_{V, E X}$ is the extended volume fraction of mush. Mirihanage and Browne [22] describe a similar approach to equiaxed solidification.

Extended volume fraction of mush is calculated on the assumption that each equiaxed dendrite is contained within a spherical envelope of mush, with phantom growth and overlapping mush volumes included in the extended volume calculation. (See reference [23] for a thorough explanation of the phantom growth and extended volume concepts in respect 
of the JMAK model.) In a transient situation, the Quasi-Static Steady (QSS) approach is used to calculate extended volume fraction of mush as follows,

$$
\zeta_{V, E X}=\frac{4 \pi}{3} \int_{0}^{t} \dot{N}\left(t_{n}\right)\left[\int_{t_{n}}^{t} v_{t i p} d t^{\prime}\right]^{3} d t_{n},
$$

where $\dot{N}\left(t_{n}\right)$ is the nucleation rate and $t_{n}$ is an intermediate time variable (interpreted as the time since nucleation); $t^{\prime}$ is another intermediate time variable used for integration purposes. The dendrite tip velocity, which has been determined experimentally [24], has the following form,

$$
v_{\text {tip }}=C_{t} \Delta T^{b},
$$

where $C_{t}$ is a dendritic growth coefficient and $b$ is a growth exponent. The undercooling at the tip is given as,

$$
\Delta T=T_{L}-T
$$

The nucleation rate, $\dot{N}(t)$, represents the number of new nuclei formed per unit volume per unit time; hence, it is a volumetric nuclei density rate. Assuming that nucleation follows a Gaussian distribution on nucleation undercooling, $\Delta T$, the nucleation rate is given as,

$$
\dot{N}(t)=\frac{\dot{T} N_{o}}{\Delta T_{\sigma} \sqrt{2 \pi}} \exp \left[-\frac{1}{2}\left(\frac{\Delta T-\Delta T_{o}}{\Delta T_{\sigma}}\right)^{2}\right],
$$

where $\dot{T}$ is the rate of change of temperature, $N_{o}$ is the maximum nuclei density, $\Delta T_{o}$ is the arithmetic mean for nucleation undercooling and $\Delta T_{\sigma}$ is the standard deviation of nucleation undercooling.

During phase change, the thermophysical properties $\left(k\right.$ and $\left.\rho c_{p}\right)$ of semisolid CVs are assumed to follow a law of mixing between the relevant liquid and solid properties. The thermal conductivity, $k$, is given generally as

$$
k=f_{s} k_{s}+\left(1-f_{s}\right) k_{l} .
$$

A similar approach is used for calculating the volumetric specific heat, $\rho c_{p}$. This law of mixing approach is adopted from literature [13]. 


\subsubsection{Boundary conditions}

The governing equation is applied to the finite volume of the sample, however, recognising that a computational domain encompassing the entire sample has symmetry in the $y$-direction, computational effort is reduced by halving that domain through the $x-z$ median plane and setting an adiabatic boundary at the plane of symmetry. The heat flux at this boundary is defined by a second kind (Neumann) boundary condition, as follows,

$$
-\left.k \frac{d T}{d y}\right|_{y=0}=0 .
$$

At the opposing boundary (i.e., where the sample meets the glass window) the heat flux is non-zero, transient, and a function of position. Therefore, a third kind (Robin) boundary condition is assumed,

$$
-\left.k \frac{d T}{d y}\right|_{y=D / 2}=h_{\text {loss }}\left(T_{\infty}-T\left(x, \frac{D}{2}, t\right)\right),
$$

where $h_{\text {loss }}$ is the heat transfer coefficient and $T_{\infty}$ is the ambient temperature in the rocket module. The heat transfer coefficient, $h_{\text {loss, }}$ is a simplification, and is intended to act as an overall coefficient for the composite structure of the quartz glass window, spacers, plastic cover, and interfaces. This simplification gives the distinct advantage that we need not determine thermal resistances for each structural component within the apparatus; instead one overall coefficient is sufficient.

The temperature at the cell interfaces in contact with PE devices at the bottom $(x=0)$ and top $(x=H)$ of the cell are defined by first kind (Dirichlet) boundary conditions, respectively, as follows,

$$
\begin{gathered}
T(0, y, t)=T_{C}(t), \\
T(H, y, t)=T_{H}(t),
\end{gathered}
$$

where $T_{C}$ and $T_{H}$ are reference temperatures. These reference temperatures were determined using linear extrapolation of the historical TC measurements from within the experimental cell.

At $x=0$ the temperature was controlled by the cooler PE (PE-C) and, at $x=H$, by the hotter PE (PE-H). Temperatures from each PE device, $T_{\mathrm{PE}-\mathrm{H}}$ and $T_{\mathrm{PE}-\mathrm{C}}$, were recorded during the full duration of the experiment. As previously mentioned, these PE temperatures were recorded at some location too far from the sample boundary to be considered for direct use in 
the boundary conditions. However, the offsets between the recorded temperatures in at the PE devices and the temperatures extrapolated at the respective PE-cell interfaces are reported as follows,

$$
\begin{aligned}
& T_{\text {offset-C}}=T_{C}-T_{P E-C} \quad, \\
& T_{\text {offset-H}}=T_{H}-T_{P E-H} .
\end{aligned} .
$$

The offset temperatures $T_{\text {offset-C }}$ and $T_{\text {offset-H }}$ relate to the cold and hot PE devices, respectively. This presentation of the data is convenient because the values for the BCs in equations (15) and (16) can be determined from the measured heater temperatures, $T_{P E-C}$ and $T_{P E-H}$, adjusted by the appropriate offset temperature, $T_{\text {offset-C }}$ or $T_{\text {offset }-H}$.

\subsection{Numerical model}

The control volume method with an explicit numerical scheme is applied to equation (2). Iteration within time steps is required due to the non-linear nature of the Scheil equation. The control volume depth is taken to be the sample width $(W)$, i.e., the typical control volume size is,

$$
V_{C V}=W \Delta x \Delta y
$$

The JMAK model requires double integration at each time step. In the model, latent heat and sensible heat are coupled through the transient heat equation. Because of the transient nature of the model, the computational burden of the double integration becomes cumbersome as time marches onwards at each point in the simulation. Heeg [25] has demonstrated a fast algorithm for treating the double integral in equation (8). This algorithm identifies four individual cumulative parameters that need only be updated at each explicit time step. Hence the need for a historical double integration is removed. Improvements to the computational speed of the current algorithm are comparable to those report in the original reference [25].

\subsubsection{Numerical domain}

Figure 5 shows the numerical domain consisting of an orthogonal fixed grid of CVs, and a cross-section of the MEDI experiment cell. The coordinate system is located such that $x=0$ corresponds to the colder PE interface with the experimental cell and $x=H$ corresponds to the hotter PE interface to the cell. The dimension $y=0$ refers to the $x-z$ median plane and $y=D / 2$ corresponds to the interface between the cell and the quartz glass window. Half-size and quarter-size control volumes are placed at the boundary interfaces and corners, respectively. 

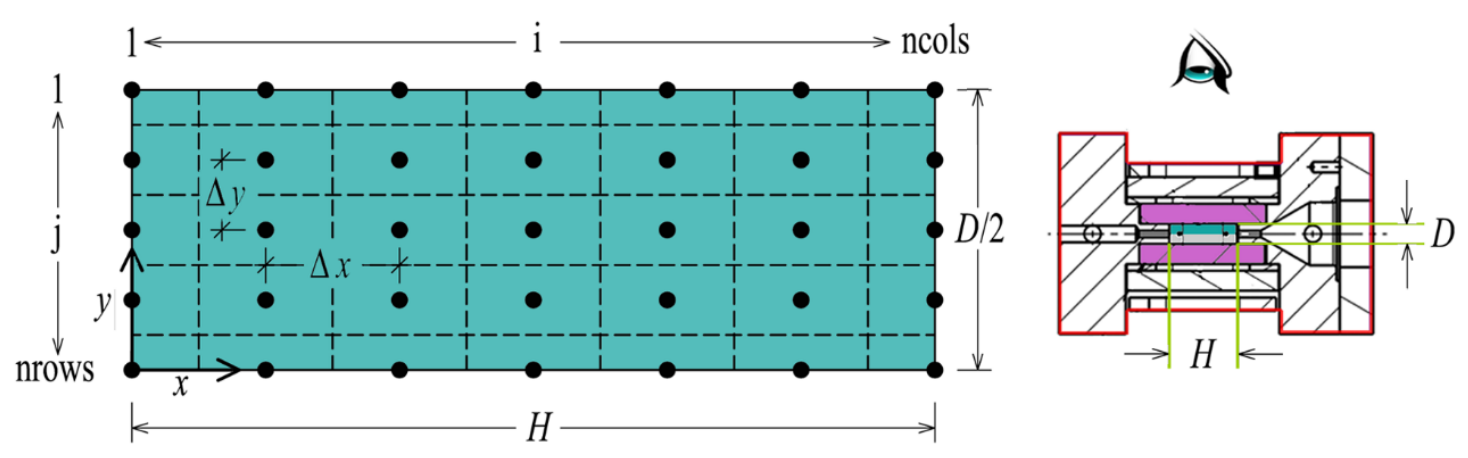

Figure 5 The numerical domain (left hand side) and orientation reference to the crosssection of the experiment cell (right hand side).

\subsubsection{Verification}

If validation is the process of finding agreement between numerically simulated and experimentally measured datasets, then verification is the process of confirming that numerical errors in the simulation are minimal. A verification step in any simulation is essential because it provides confidence in a numerical scheme before comparisons with experimental data are attempted [5].

Complete verification of the numerical code requires a closed form analytical solution (for comparison purposes) as demonstrated in [26]. However, where a closed form solution is not available (as is the case here) verification of the numerical scheme is achievable through a grid refinement study [27]. A grid refinement study involves comparison of simulation results from three different grid resolutions. Where the grid refinement factor $(\lambda)$ is fixed, i.e., $\lambda=\Delta x_{2} / \Delta x_{1}=\Delta x_{3} / \Delta x_{2}$ and $\lambda=\Delta y_{2} / \Delta y_{1}=\Delta y_{3} / \Delta y_{2}$, the observed order of accuracy of the numerical scheme $(p)$ can be calculated as follows,

$$
p=\frac{\ln \left(\frac{T_{\text {sim }_{3}}-T_{\text {sim }_{2}}}{T_{\operatorname{sim}_{2}}-T_{\text {sim }_{1}}}\right)}{\ln \lambda},
$$

where $T_{\text {sim }}$ is the full numerical solution and the subscript refers to the level of grid refinement, in this case level 1 is the finest grid, level 2 is the median grid and level 3 is the coarsest grid. The comparison of the numerical solutions is made convenient when grid points at each grid resolution align exactly as the grid is refined. Given the temperature field from three simulations, the $L_{2}$ norm is employed to make each comparison, for example, as follows, 


$$
T_{\text {sim } 2}-T_{\text {sim } 1}=\frac{1}{n_{C V s}} \sqrt{\sum_{i, j}^{n_{C V s}}\left(T_{\operatorname{sim} 2(i, j)}-T_{\operatorname{sim} 1(i, j)}\right)^{2}},
$$

where the subscripts $i$ and $j$ refer to the grid points of the more coarse grid (the grid coordinates of which are common to both grids), and $n_{C V s}=$ nrows $\times$ ncols of the more coarse grid. If $p$ is adequately close to the expected formal order of accuracy then the scheme is deemed to be verified. The expected formal order of accuracy in our case is two.

\subsubsection{Simulation inputs}

Table 2 shows the simulation specific inputs to the numerical model.

Table 2 Simulation specific inputs.

\begin{tabular}{lccc}
\hline Input & Symbol & Value & Units \\
\hline Simulation start time (relative to lift off) & $t_{\text {start }}$ & -300 & {$[\mathrm{~s}]$} \\
Simulation end time (relative to lift off) & $t_{\text {end }}$ & 550 & {$[\mathrm{~s}]$} \\
Nominal cooling rate (from $t=-235 \mathrm{~s})$ & $\dot{T}$ & -0.75 & {$[\mathrm{~K} / \mathrm{min}]$} \\
Grid size in $x$ (ncols=33) & $\Delta x$ & 0.3125 & {$[\mathrm{~mm}]$} \\
Grid size in $y$ (nrows=9) & $\Delta y$ & 0.1875 & {$[\mathrm{~mm}]$} \\
Numerical time step & $\Delta t$ & 0.05 & {$[\mathrm{~s}]$} \\
Heat transfer coefficient at $y=D / 2$ & $h_{l o s s}$ & 0.85 & {$\left[\mathrm{~W} / \mathrm{m}^{2} \mathrm{~K}\right]$} \\
Ambient environment temperature & $T_{\infty}$ & 303.15 & {$[\mathrm{~K}]$} \\
Dendrite growth coefficient [24] & $C_{t}$ & $6.54469 \times 10^{-10}$ & {$\left[\mathrm{~m} / \mathrm{s} / \mathrm{K}^{4}\right]$} \\
Dendrite growth exponent $[24]$ & $b$ & 4 & {$[-]$} \\
Nuclei density & $N_{\mathrm{o}}$ & $9 \times 10^{9}$ & {$\left[/ \mathrm{m}^{3}\right]$} \\
Mean nucleation undercooling & $\Delta T_{\mathrm{o}}$ & 9.5 & {$[\mathrm{~K}]$} \\
Standard deviation of nuc. undercooling & $\Delta T_{\sigma}$ & 0.55 & {$[\mathrm{~K}]$} \\
\hline
\end{tabular}

Various grid sizes were applied in the verification procedure, ranging from $\Delta x=1.25 \mathrm{~mm}$ (ncols=9) to $\Delta x=0.078125 \mathrm{~mm}$ (ncols $=129)$, and $\Delta y=1.5 \mathrm{~mm}$ (nrows=3) to $\Delta y=0.046875 \mathrm{~mm}$ (nrows=33). As will be shown in the verification results section, the grid resolution listed in Table 2 is adequate. The nucleation data shown have been determined through an alternative investigation into the nucleation kinetics. The results from that investigation are deemed to be beyond the scope of the current manuscript.

\section{Results}

\subsection{Experiment results}

Figure 6 shows the measured thermal history for the hot PE and cool PE, and at the three TC locations inside the cell volume containing the sample. 


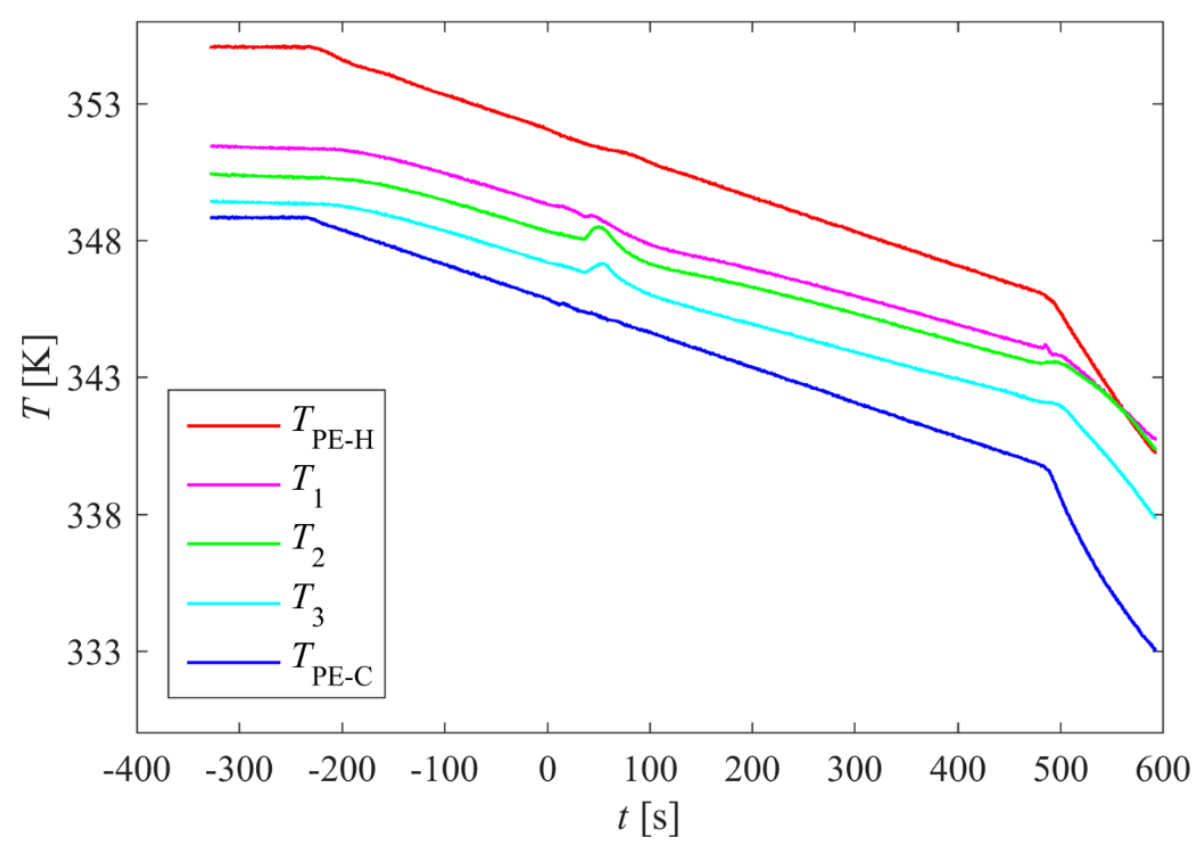

Figure 6 MEDI experiment measured thermal history at the hot $\left(T_{\mathrm{PE}-\mathrm{H}}\right)$ and cool $\left(T_{\mathrm{PE}-\mathrm{C}}\right)$ Peltier element devices, and at the three thermocouple locations, $x=1.4 \mathrm{~mm}\left(T_{3}\right), x=4.9$ $\mathrm{mm}\left(T_{2}\right)$, and $x=8.2 \mathrm{~mm}\left(T_{1}\right)$.

Figure 7 shows a plot of the temperature differences $\left(T_{\text {offset } H}\right.$ and $\left.T_{\text {offset-C}}\right)$ between the PE measured temperatures and that extrapolated from the TCs (inside the experimental cell). The results from a fitting exercise for each offset are shown.

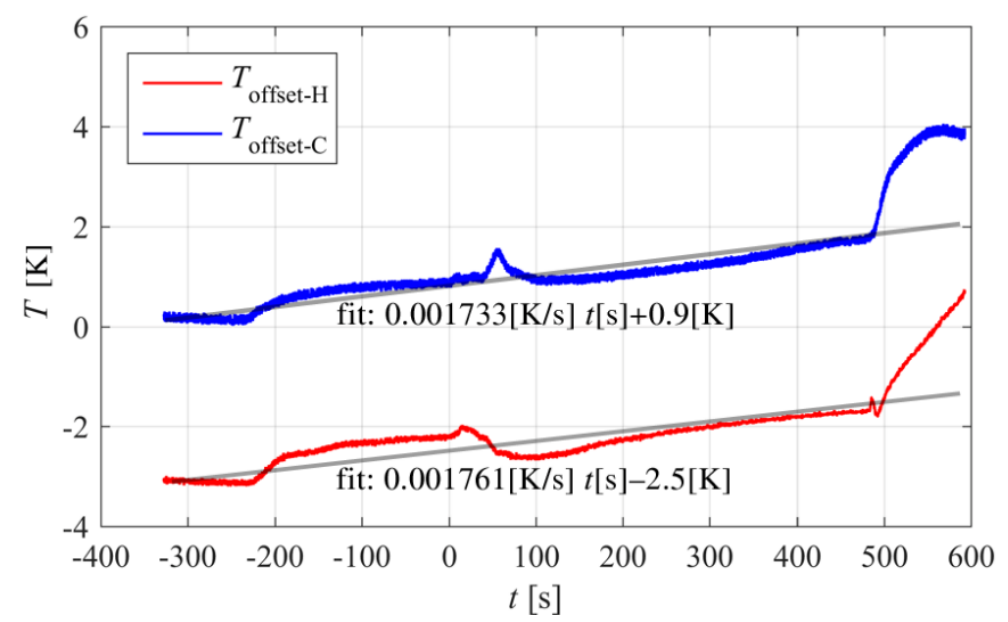

Figure 7 Hot side offset (red) and cold side offset (blue) for each PE device. (Linear fits with fitting data provided). [Refer to equations (17) and (18)]

\subsection{Numerical results}

\subsubsection{Verification results}

Figure 8 shows a plot of the observed order of accuracy $(p)$ with respect to the number of 
control volumes in the domain ( $n_{C V s}=$ ncols $\times$ nrows) at the median grid resolution (level 2 in equation (20)) of the verification procedure. Results corresponding to three median grid resolutions: a coarse grid $(17 \times 5)$, a medium grid $(33 \times 9)$, and a fine grid $(65 \times 17)$, are shown.

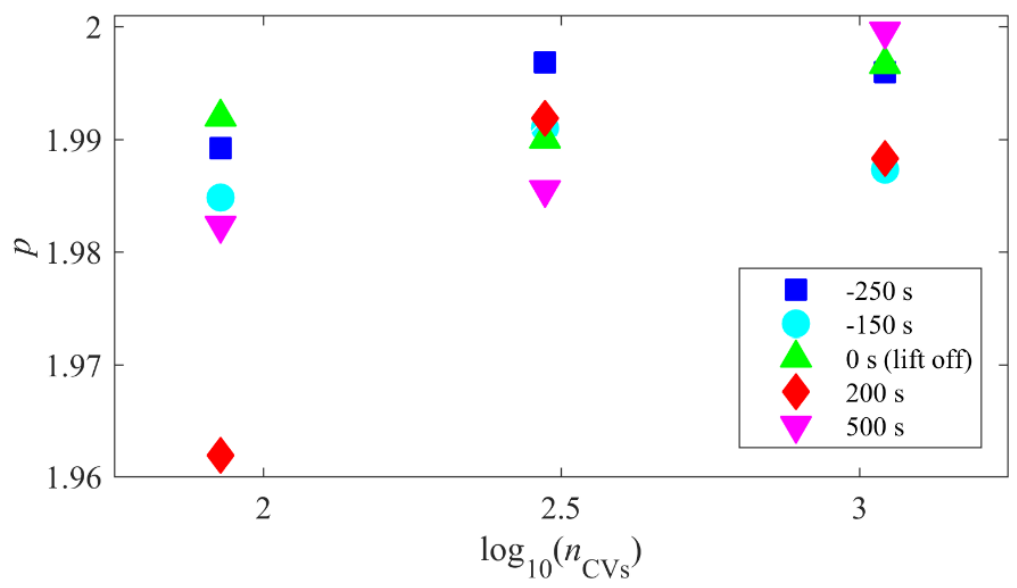

Figure 8 Numerical scheme order of accuracy, $p$, as a function of the number of control volumes, $n_{C V s}$, in the numerical domain at various simulation times. [Refer to equation (20)]

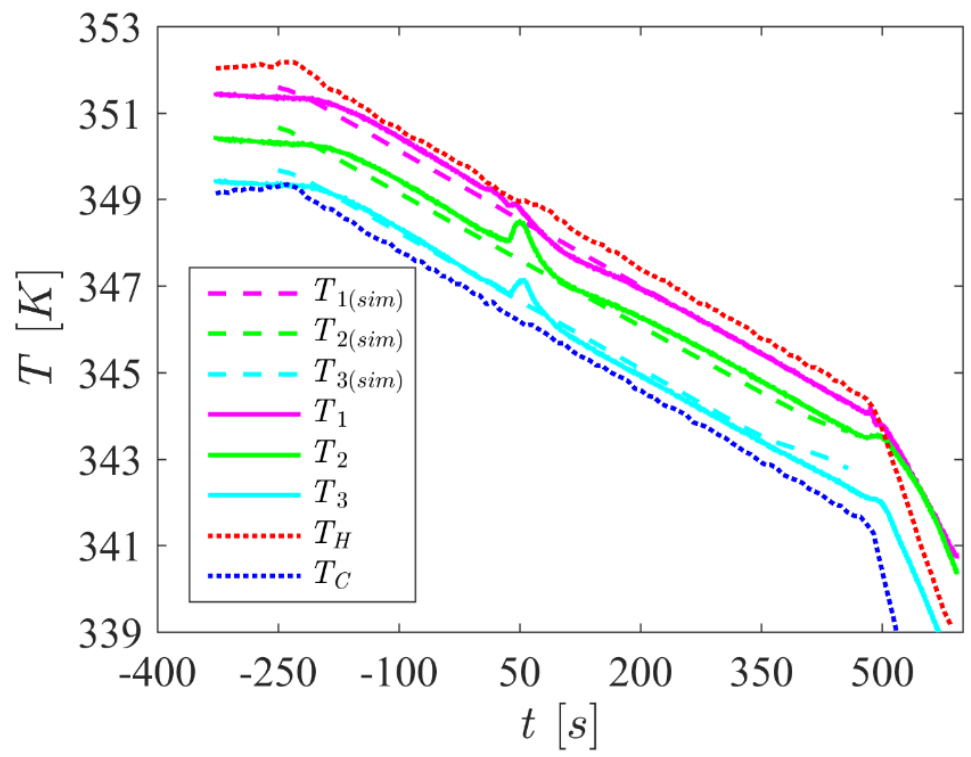

Figure 9 Simulated thermal history (Scheil approach, dashed lines) superimposed on the experiment thermal history (solid lines) at the three thermocouple locations, $x=1.4 \mathrm{~mm}$ $\left(T_{3}\right), x=4.9 \mathrm{~mm}\left(T_{2}\right)$, and $x=8.2 \mathrm{~mm}\left(T_{1}\right)$, and the estimated PE interface temperatures, $x=0 \mathrm{~mm}\left(T_{C}\right)$ and $x=10 \mathrm{~mm}\left(T_{H}\right)$. 


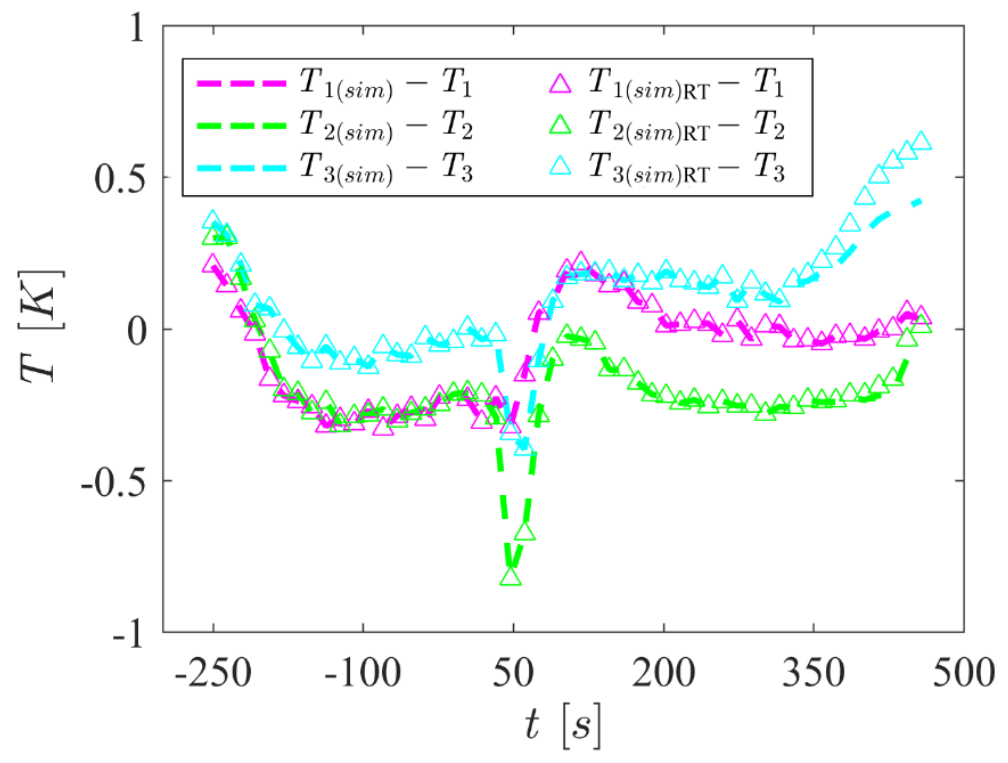

Figure 10 Difference between the simulated and measured thermal history at three thermocouple locations. Sub-script 'RT' specifically refers to the simulation where internal solid fraction was calculated using the method of Rappaz and Thévoz (equation (6) ref. [16]). Otherwise, Scheil (equation (5)) was used.

Figure 9 shows the simulated thermal history (dashed lines) superimposed on the experimental thermal history (solid lines) at each of the three TC locations. The hot side $\left(T_{H}\right)$ and cool side $\left(T_{C}\right)$ reference temperatures are shown (as dotted lines). Figure 10 shows the difference between the simulated and measured thermal history at each of the three TCs locations; included here are data for a comparative simulation carried out where the internal solid fraction, $g_{s}$, is calculated using the method of Rappaz and Thévoz [16].

Figure 11 shows a typical thermal profile calculated using the numerical model with Scheil; a contoured plot of temperature is shown (results are mirrored about the adiabatic boundary at $y=0)$.

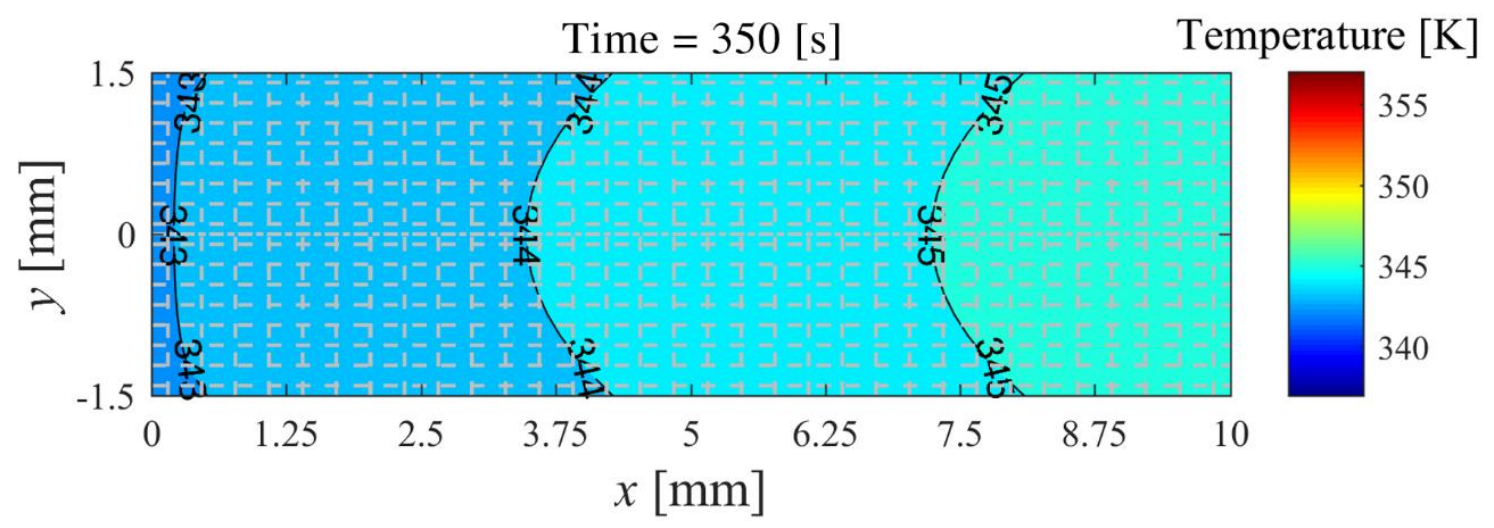

Figure 11 Typical thermal profile of the numerical domain at time: $t=350 \mathrm{~s}$. The solution is mirrored about $y=0$. Control volumes boundaries are shown as dashed lines. Equation (5) used. 


\section{Discussion}

\subsection{Experimental measurements}

\subsubsection{Thermal disturbance due to rocket de-spinning}

Figure 6 shows the measured thermal history of the MEDI experiment. Disturbances were observed on the three internal thermocouples at around $t=30 \mathrm{~s}$. These disturbances coincided with the sharp reduction in the angular momentum of the rocket known as de-spinning. During the launch and motoring phase, sounding rockets spin around their axis. Prior to the microgravity phase the rocket must de-spin. The de-spinning event caused the unwanted artefacts in the thermal results due to induced convective mixing in the liquid. Nevertheless, the thermal transients associated with this de-spinning event had sufficient time to terminate and temperature histories had stabilised (at about $t=100 \mathrm{~s}$ ) before the first observed nucleation event. All equiaxed dendrites appearing in the sample (the first of which appeared at $t=169 \mathrm{~s}$ ) remained stationary in a quiescent liquid phase; thus allaying any concerns with the de-spinning event.

\subsubsection{Temperature offsets}

Figure 7 shows the calculated temperature differences $T_{\text {offset } H}$ and $T_{\text {offset-C. }}$ A linear fitting exercise was performed and lines of best fit were established for each temperature dataset, as follows (units shown in square brackets),

$$
\begin{aligned}
& T_{\text {offset } H}(t)=1.761 \times 10^{-3}[\mathrm{~K} / \mathrm{s}] t[\mathrm{~s}]-2.5[\mathrm{~K}] \\
& T_{\text {offset } C}(t)=1.733 \times 10^{-3}[\mathrm{~K} / \mathrm{s}] t[\mathrm{~s}]+0.9[\mathrm{~K}]
\end{aligned}
$$

The offsets varied linearly with time. These functions are reported for practical convenience; interface temperatures, $T_{H}$ and $T_{C}$, may be reconstructed using recorded flight data from each PE device with the appropriate offset applied. 


\subsection{Modelling and simulation}

\subsubsection{Comparative analysis of solid fraction models}

As mentioned in Section 3.1.1, two approaches to solid fraction evolution were investigated: a Scheil approach using equation (5) and a Rappaz and Thévoz [16] approach using equation (6). In order, to calculate the grain Péclet number in the Rappaz Thévoz equation, the average grain radius in each CV was used. As shown in Figure 10, the differences in thermal history between the two approaches were found to be negligible with only a slight deviation observable at the end of the microgravity period where the Rappaz Thévoz approach gave a slightly higher prediction of temperature. This higher temperature prediction was due to a higher solid fraction estimate from the Rappaz Thévoz approach. Figure 12 shows the overall solid fraction evolution for the entire cell as predicted by the respective models. The calculations gave an upper value of 0.042 using Scheil and 0.064 using Rappaz-Thévoz. Accounting for the axial thermal gradient, the peak solid fraction values in the simulations were recorded near the cold interface. The peak values were 0.18 based on Scheil and 0.20 based on Rappaz-Thévoz. The low solid fraction levels and low diffusivity of solute in liquid explain why negligible differences existed between the simulated thermal histories reported in Figure 10.

To provide context, we consider that the temperature differences between the Scheil and Rappaz-Thévoz simulations are less than the expected systematic error for the thermocouples (which had a measurement uncertainty range of $+/-0.75 \%$ ). The following discussion points refer specifically to results generated using the Scheil approach, but would also apply generally to results generated using the Rappaz Thévoz method. 


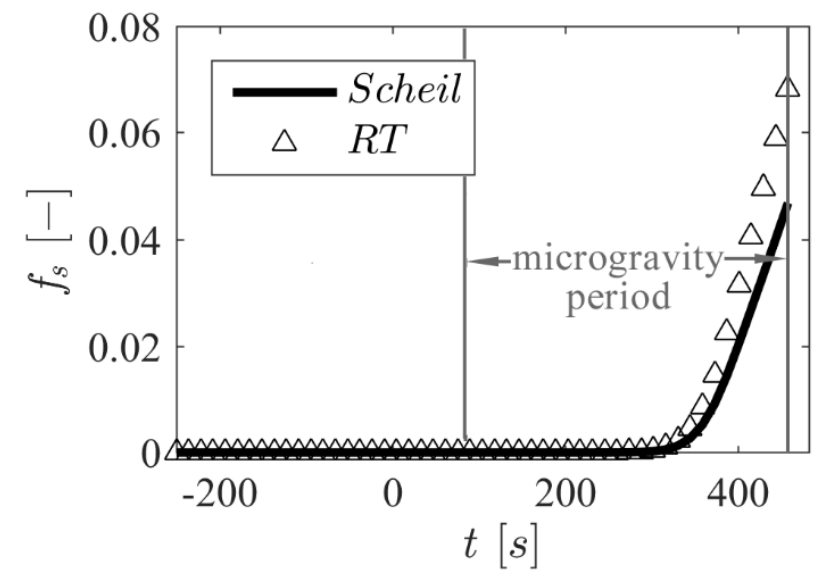

Figure 12 Overall solid fraction in the entire cell plotted against time, as predicted using the Scheil-based model, equation (5), and Rappaz and Thévoz model, equation (6), to calculate the internal solid fraction within the mush.

\subsubsection{Dimensionality of the model}

A question arises on the correct form of the heat equation and whether a 1D, 2D, or 3D model should have been applied. Initially, it was assumed that a 1D-heat equation in the $x$ direction with an additional term for lateral heat loss to the environment would suffice (similar to the approach found in reference [28]). Several unsatisfactory attempts were made using the 1D approach and a decision was made to expand the dimensionality of the model. After reviewing the solidification sequences in the $x$ - $z$ plane and upon observing the uniform directionality of the equiaxed front in the $z$-direction, evidence supported the assumption that temperature gradients in the $z$-direction were marginal and could be ignored.

Thermocouples were aligned with the $x$ - $z$ median plane only; hence it was impossible to distinguish thermal data in the $y$-direction. Furthermore, camera angles could not provide distinct solidification data on the $x-y$ plane.

Because quartz glass windows were used to contain the alloy on both sides in the $y$ direction, thermophysical properties of materials in $y$-direction were reviewed. Specific focus was placed on thermal conductivities and geometry. The thermal conductivities of the alloy in both liquid and solid state are lower than that of the glass window ( $\left.k_{\text {glass }}=1.3 \mathrm{~W} / \mathrm{mK}\right)$. Thermal resistance is given as $R_{T}=L_{c h a r} / k A$, where $L_{c h a r}$ is characteristic length and $A$ is surface area. The characteristic length of the experimental cell was taken as half of its depth in the $y$-direction $(1.5 \mathrm{~mm})$, whereas the characteristic length of the glass was taken as the full thickness $(3 \mathrm{~mm})$. The ratio of thermal resistances $\left(R_{\text {alloy }} / R_{\text {glass }}\right)$ was in the range 2.4 (solid alloy-glass interface) to 5 (liquid alloy-glass interface). As a heuristic rule, when the 
ratio of internal to external thermal resistances is greater than 0.1 then temperature gradients in the structure should be considered [29].

The absence of measured data in the $y$-direction and the concern raised by the ratios in thermal resistances confirmed the decision to proceed with a 2-dimensional model of heat flow in the $x-y$ plane. Ultimately, however, temperature variation in the $y$-direction was predicted to be less than $0.22 \mathrm{~K}$.

\subsubsection{Simulation verification}

The expected order of accuracy of the numerical scheme is two; from Figure 8 it is clear that the observed order of accuracy $(p)$ converged towards this value as the grid resolution was refined. This shows that errors associated with the higher order terms omitted from the difference equations (terms associated with a Taylor series approximation of the partial derivatives) were approximately zero and may therefore be neglected [27]. The scheme is adequately converged at the medium $(33 \times 9)$ and fine $(65 \times 17)$ grids; both grids having $p>1.98$. Simulations results were processed using the medium grid.

\subsubsection{Simulated thermal histories}

Figure 9 shows the simulated thermal histories and the measured thermal history at each thermocouple position within the sample. Furthermore, Figure 10 shows the differences between the simulated and experimentally measured temperatures at each thermocouple against time. The largest deviation between simulated and measured data is less than $0.9 \mathrm{~K}$ and is due to a transient deviation caused by the rocket de-spinning. Otherwise, during the microgravity phase ( $t=89 \mathrm{~s}$ to $t=468 \mathrm{~s}$ ), the maximum temperature differences between simulated and measured temperatures were less than $0.4 \mathrm{~K}$ for $T_{1}$, less than $0.8 \mathrm{~K}$ for $T_{2}$, and less than $0.4 \mathrm{~K}$ for $T_{3}$. The root mean squares of the differences during the entire simulation were $0.18 \mathrm{~K}$ at $T_{1}, 0.27 \mathrm{~K}$ at $T_{2}$, and $0.20 \mathrm{~K}$ at $T_{3}$. The root mean square (RMS) of the differences during the microgravity period were $0.09 \mathrm{~K}$ at $T_{1}, 0.21 \mathrm{~K}$ at $T_{2}$, and $0.22 \mathrm{~K}$ at $T_{3}$.

Figure 11 shows the temperature field and several isotherms over the numerical domain at time $t=350 \mathrm{~s}$. It is clear that simulated isotherms are curved, which indicates biaxial heat flow in $x$ and $y$ directions. 


\subsubsection{Boundary conditions}

The heat loss at the interface to the quartz glass is characterised by the coefficient $h_{\text {loss }}$ at the boundary where $y=D / 2$. Figure 9 shows the optimal result with $h_{\text {loss }}$ set at $0.85 \mathrm{~W} / \mathrm{m}^{2} \mathrm{~K}$. This optimal value of coefficient was determined after a sensitivity analysis where a parameter variation on $h_{\text {loss }}$ was applied to the model. Figure 13 shows demonstrative results of the simulated temperature histories with $h_{\text {loss }}$ set low at $0.425 \mathrm{~W} / \mathrm{m}^{2} \mathrm{~K}$ and high at $1.7 \mathrm{~W} / \mathrm{m}^{2} \mathrm{~K}$. The Root Mean Square (RMS) of the error between simulated and measured temperatures was determined over the microgravity period for each simulation run. The optimal setting with $h_{\text {loss }}=0.85 \mathrm{~W} / \mathrm{m}^{2} \mathrm{~K}$ gave an RMS of $0.2 \mathrm{~K}$. A $10 \%$ increase in $h_{\text {loss }}$ above the optimum yielded an RMS of $0.25 \mathrm{~K}$; whereby, a decrease of $10 \%$ below the optimum yielded an RMS of $0.21 \mathrm{~K}$. Hence, a $h_{\text {loss }}$ parameter setting of $0.85 \mathrm{~W} / \mathrm{m}^{2} \mathrm{~K}$ returned the minimum RMS value and was therefore deemed optimal.

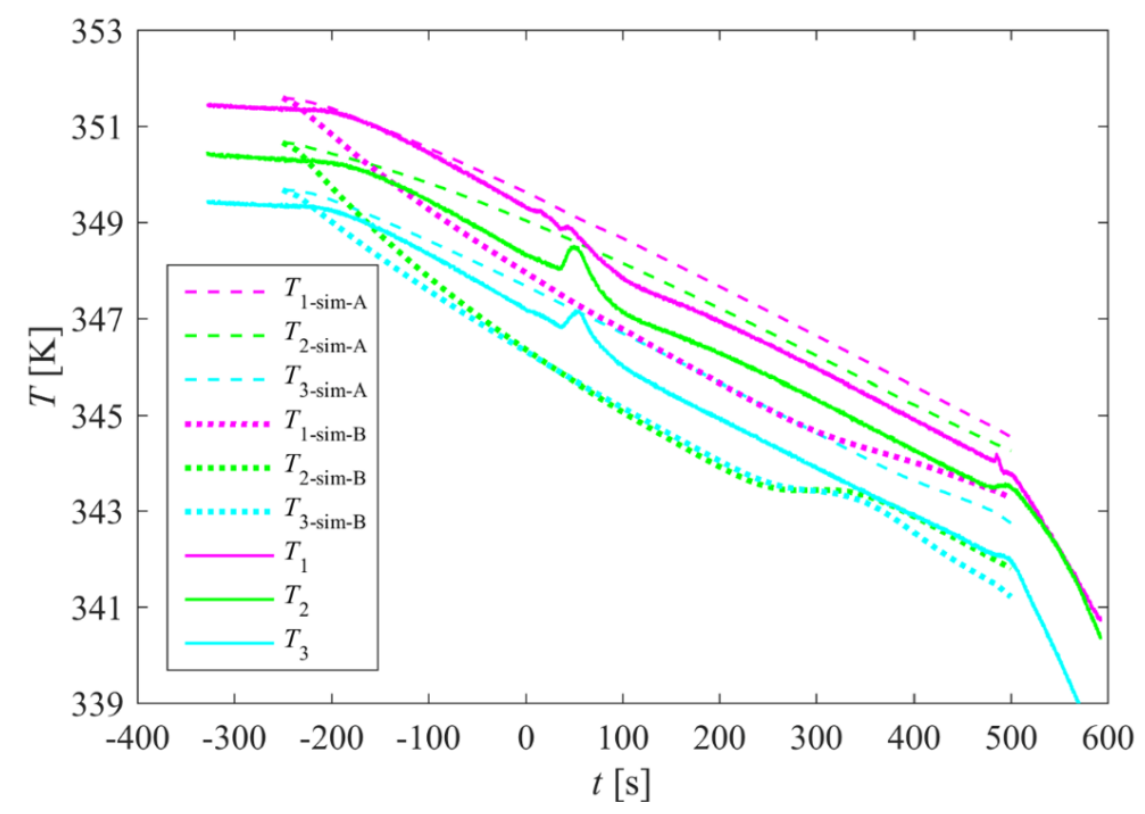

Figure 13 Simulated thermal history with $h_{\text {loss }}=0.425 \mathrm{~W} / \mathrm{m}^{2} \mathrm{~K}$ (simulation-A) and $h_{\text {loss }}=1.7 \mathrm{~W} / \mathrm{m}^{2} \mathrm{~K}$ (simulation-B) superimposed on the experiment thermal history (solid lines) at locations, $x=1.4 \mathrm{~mm}\left(T_{3}\right), x=4.9 \mathrm{~mm}\left(T_{2}\right)$, and $x=8.2 \mathrm{~mm}\left(T_{1}\right)$.

\subsection{Further results for discussion}

At any given time, isotherm curvatures show a tendency to increase with temperature along the sample. This feature of the results is explained by examining the lateral heat flux in the $y$ direction. The temperature difference, $T_{\infty}-T(x, D / 2, t)$, causes the heat flux on the quartz glass interface perpendicular to the $x-z$ plane. As shown in Figure 14 (a), the heat flux at the 
quartz glass interface increases in the $x$-direction. In other words, at higher temperatures in the sample more heat is lost in the lateral direction.

(a)

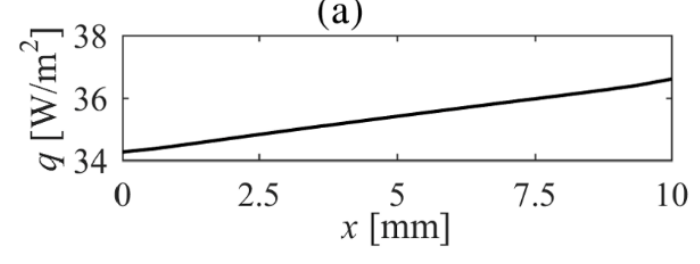

(c)

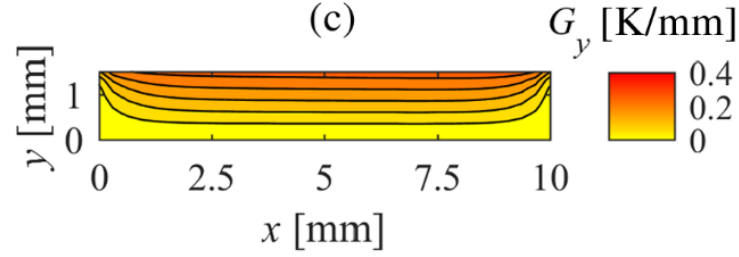

(b)

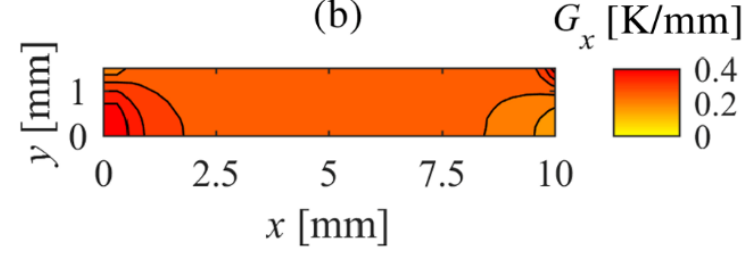

(d)

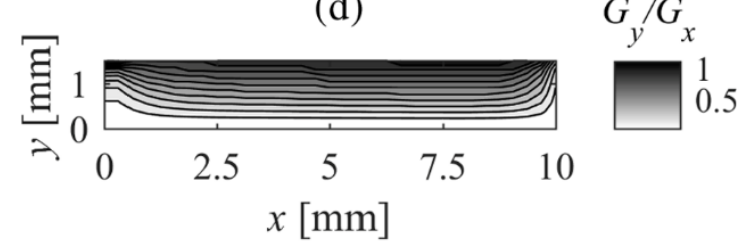

Figure 14 (a) Heat flux at the domain boundary: $y=D / 2$. (b) Temperature gradient in the $x$ direction. (c) Temperature gradient in the $y$-direction. (d) Ratio of temperature gradient in the $y$-direction to temperature gradient in the $x$-direction. (All plots are for time: $t=350 \mathrm{~s}$.)

It is also interesting to examine the temperature gradients in the $x$ and $y$ directions, $G_{x}=\mathrm{d} T / \mathrm{d} x$ and $G_{y}=\mathrm{d} T / \mathrm{d} y$, respectively. Figure 14 (b) shows that $G_{x}$ is about $0.3 \mathrm{~K} / \mathrm{mm}$ over the majority of the domain. In Figure 14(c) we see that $G_{y}$ is zero at the axis of symmetry $(y=0)$ and reaches a maximum along the $y=D / 2$ boundary. The maximum lateral gradient at this interface is about $0.3 \mathrm{~K} / \mathrm{mm}$. Figure 14(d) shows the ratio of the temperature gradients $\left(G_{y} / G_{x}\right)$. The results show that uniaxial temperature gradient conditions exist in the $x$ direction along the median plane, $y=0$, but equi-biaxial temperature gradients exist near the boundary to the quartz glass, $y=D / 2$. However, due to the low thickness of the sample in the $y$-direction, the maximum temperature difference between the sample centre and the quartzglass interface at any $x$ position is less than $0.22 \mathrm{~K}$.

\section{Conclusion}

The objectives of this work, as previously stated in Section 1.1, were:

(1) Describe the MEDI experimental set-up and procedures.

(2) Develop an appropriate thermal model of the experiment.

(3) Provide confidence in the model's numerical scheme and results.

(4) Provide an assessment of the thermal conditions experienced during the experiment.

The MEDI experimental material, apparatus, and procedures were explained and measured thermal data was provided. 
The details of an appropriate 2D thermal model of the experiment were described. The model allowed for transient heat flow with internal latent heat generation based on a continuous nucleation scheme (a Gaussian nucleation distribution). A fast algorithm was implemented into the model, which allowed for an order of magnitude improvement in the computational processing speed. A comparative analysis of internal equiaxed solid fraction was performed using an internal Scheil microsegregation model versus an analytical Rappaz and Thévoz [16] model. The different approaches gave comparable thermal results, but the RappazThévoz model gave slightly higher solid fraction predictions. The experimental results did not permit a direct validation against solid fraction evolution, but given the available temperature data, the internal Scheil approach gave marginally better agreement accounting for latent heat release. It was concluded that for the purposes of thermal characterisation (which is the main aim of this manuscript) the differences between a Scheil and a RappazThévoz approach were negligible for this alloy up to undercooling levels and solid fractions experienced during the experiment.

A formal verification procedure was performed on the model and satisfactory results were obtained. The model was shown to converge with second order accuracy; thus providing confidence in the discretisation scheme selected for the numerical model.

The model was applied to assess the thermal conditions during the experiment. Comparisons between simulated thermal histories and the measured thermal data showed good agreement because suitable boundary conditions were developed for all interfacing planes of the domain. Through extensive investigation, a suitable heat loss coefficient was determined for the domain boundary where the alloy was in contact with the viewing window. To reduce computational burden, an adiabatic boundary was applied at the plane of symmetry. The model showed that a consistent axial temperature gradients, $G_{x}$, of $0.3 \mathrm{~K} / \mathrm{mm}$ was achieved as expected. The model predicted varying lateral temperature gradients, $G_{y}$, ranging from 0.0 to $0.3 \mathrm{~K} / \mathrm{mm}$. However, the resulting temperature variation in the $y$ direction was marginal - variation of no more than $0.22 \mathrm{~K}$ from the median plane to the quartz glass interface at any given height over all times.

Bellet et al. [5] highlight the importance of comparative benchmarking in the model development process using the example of columnar solidification. Benchmark data is required for comparison purposes. However, experimental validation is an important procedure in solidification modelling. The results from this investigation may be used as experimental benchmark data towards the verification and validation of models where 
multiple equiaxed diffusion-controlled solidification is assumed. For future reference, Table 1 provides a summary of all the thermophysical data for the alloy. Table 2 provides the simulation data developed and used throughout this analysis. The dataset from this research have been made available for download from [McFadden, Shaun; Mooney, Robin Patrick; Sturz, Laszlo; Zimmermann, Gerhard (2017), "MEDI microgravity experiment Thermal Dataset", Mendeley Data, v2] with acknowledgement to the European Space Agency CETSOL Programme.

\section{Acknowledgments}

The authors would like to acknowledge the financial support of ESA PRODEX [contract number 4000107132] via Enterprise Ireland, German BMWi/DLR [contract number FKZ 50WM1443], and ESA [contract number AO-99-117, CETSOL]. Airbus Defence \& Space, SSC, OHB System AG and DLR-Moraba are gratefully acknowledged for MEDI hardware development and MASER-13 mission support. Figure 1 and Figure 2 were used with permission of Airbus Defence \& Space.

\section{Bibliography}

[1] R. Mooney, S. Rex, L. Froyen, S. McFadden, O. Budenkova, D. Voss, B. Schmitz, Y. Fautrelle, A. Kartavykh, D. Browne, Review of the maxus 8 sounding rocket experiment to investigate solidification in a ti-al-nb alloy, (2011). doi:1609-042X.

[2] H. Nguyen-Thi, G. Reinhart, G. Salloum Abou Jaoude, R.H. Mathiesen, G. Zimmermann, Y. Houltz, D. Voss, a. Verga, D.J. Browne, a. G. Murphy, XRMONGF: A novel facility for solidification of metallic alloys with in situ and time-resolved $\mathrm{X}$-ray radiographic characterization in microgravity conditions, J. Cryst. Growth. 374 (2013) 23-30. doi:10.1016/j.jcrysgro.2013.03.032.

[3] L. Sturz, G. Zimmermann, Comparison of results from low-gravity and normal gravity experiment "TRACE" on the columnar-equiaxed transition in the transparent alloy system Neopentylglycol-Camphor, in: ESA Spec. Publ. 700SP, European Space Agency, 2011: pp. 459-466.

[4] L. Hachani, K. Zaidat, B. Saadi, X.D. Wang, Y. Fautrelle, Solidification of Sn-Pb alloys: Experiments on the influence of the initial concentration, Int. J. Therm. Sci. 91 (2015) 34-48. doi:10.1016/j.ijthermalsci.2015.01.007. 
[5] M. Bellet, H. Combeau, Y. Fautrelle, D. Gobin, M. Rady, E. Arquis, O. Budenkova, B. Dussoubs, Y. Duterrail, A. Kumar, C.A. Gandin, B. Goyeau, S. Mosbah, M. Založnik, Call for contributions to a numerical benchmark problem for 2D columnar solidification of binary alloys, Int. J. Therm. Sci. 48 (2009) 2013-2016. doi:10.1016/j.ijthermalsci.2009.07.024.

[6] C.-A. Gandin, B. Billia, G. Zimmermann, D.J. Browne, M.D. Dupouy, G. Guillemot, H. Nguyen-Thi, N. Mangelinck-Noël, G. Reinhart, L. Sturz, S. McFadden, J. Banaszek, Y. Fautrelle, K. Zaïdat, A. Ciobanas, Columnar-to-Equiaxed Transition in SOLidification Processing (CETSOL): A Project of the European Space Agency (ESA) - Microgravity Applications Promotion (MAP) Programme, Mater. Sci. Forum. 508 (2006) 393-404. doi:10.4028/www.scientific.net/MSF.508.393.

[7] G. Zimmermann, L. Sturz, B. Billia, N. Mangelinck-Noël, H.N. Thi, C. Gandin, D.J. Browne, W.U. Mirihanage, Investigation of columnar-to-equiaxed transition in solidification processing of AlSi alloys in microgravity - The CETSOL project, J. Phys. Conf. Ser. 327 (2011) 12003. doi:10.1088/1742-6596/327/1/012003.

[8] G. Zimmermann, L. Sturz, H. Nguyen-Thi, N. Mangelinck-Noel, Y.Z. Li, C.A. Gandin, R. Fleurisson, G. Guillemot, S. McFadden, R.P. Mooney, P. Voorhees, A. Roosz, A. Ronaföldi, C. Beckermann, A. Karma, C.H. Chen, N. Warnken, A. Saad, G.U. Grün, M. Grohn, I. Poitrault, T. Pehl, I. Nagy, D. Todt, O. Minster, W. Sillekens, Columnar and Equiaxed Solidification of Al-7 wt.\% Si Alloys in Reduced Gravity in the Framework of the CETSOL Project, JOM. 69 (2017) 1269-1279. doi:10.1007/s11837-017-2397-4.

[9] V.T. Witusiewicz, L. Sturz, U. Hecht, S. Rex, Thermodynamic description and unidirectional solidification of eutectic organic alloys: III. Binary systems neopentylglycol-(d)camphor and amino-methyl-propanediol-(d)camphor, Acta Mater. 52 (2004) 5519-5527. doi:10.1016/j.actamat.2004.08.012.

[10] L. Sturz, M. Wu, G. Zimmermann, A. Ludwig, M. Ahmadein, Benchmark experiments and numerical modelling of the columnar-equiaxed dendritic growth in the transparent alloy Neopentylglycol-(d)Camphor, in: IOP Conf. Ser. Mater. Sci. Eng., 2015. doi:10.1088/1757-899X/84/1/012086.

[11] Ü. Bayram, S. Aksöz, N. Maraşl1, Dependency of thermal conductivity on the temperature and composition of d-camphor in the neopentylglycol-d-camphor alloys, 
Thermochim. Acta. 531 (2012) 12-20. doi:10.1016/j.tca.2011.12.021.

[12] D.J. Browne, J.D. Hunt, A Fixed Grid Front-Tracking Model of the Growth of a Columnar Front and an Equiaxed Grain during Solidification of an Alloy, Numer. Heat Transf. Part B Fundam. 45 (2004) 395-419. doi:10.1080/10407790490430606.

[13] S. McFadden, D.J. Browne, A front-tracking model to predict solidification macrostructures and columnar to equiaxed transitions in alloy castings, Appl. Math. Model. 33 (2009) 1397-1416.

[14] B. Mondal, S.C. Mishra, Numerical analysis of solidification of a 3-D semitransparent medium in presence of volumetric radiation, Int. J. Therm. Sci. 48 (2009) 1116-1128. doi:10.1016/j.ijthermalsci.2008.10.001.

[15] M. Rappaz, P. Thévoz, Solute diffusion model for equiaxed dendritic growth, Acta Metall. 35 (1987) 1487-1497. doi:10.1016/0001-6160(87)90094-0.

[16] M.Rappaz, P.H.Thévoz, Solute diffusion model for equiaxed dendritic growth: Analytical solution, Acta Metall. 35 (1987) 2929-2933. doi:10.1016/00016160(87)90292-6.

[17] W.A. Johnson, R.F. Mehl, Reaction kinetics in processes of nucleation and growth, Trans. Aime. 135 (1939) 396-415.

[18] M. Avrami, Kinetics of Phase Change. I General Theory, J. Chem. Phys. 7 (1939) 1103. doi:10.1063/1.1750380.

[19] M. Avrami, Kinetics of Phase Change. II Transformation-Time Relations for Random Distribution of Nuclei, J. Chem. Phys. 8 (1940) 212. doi:10.1063/1.1750631.

[20] M. Avrami, Granulation, Phase Change, and Microstructure Kinetics of Phase Change. III, J. Chem. Phys. 9 (1941) 177. doi:10.1063/1.1750872.

[21] A.N. Kolmogorov, No Title, Bull. Acad. Sci. URSS (Sci. Math. Nat.). 3 (1937) 355.

[22] W.U. Mirihanage, D.J. Browne, Combined analytical/numerical modelling of nucleation and growth during equiaxed solidification under the influence of thermal convection, Comput. Mater. Sci. 46 (2009) 777-784. doi:10.1016/j.commatsci.2009.04.016.

[23] M. Tomellini, M. Fanfoni, Why phantom nuclei must be considered in the JohnsonMehl-Avrami-Kolmogoroff kinetics, Phys. Rev. B. 55 (1997) 14071-14073. 
doi:10.1103/PhysRevB.55.14071.

[24] L. Sturz, M. Hamacher, G. Zimmermann, In-situ observation of equiaxed dendritic growth and interaction in microgravity, in: Z. Fan (Ed.), 6th Decenn. Int. Conf. Solidif. Process. SP17, Old Windsor, UK, 2017: pp. 300-303.

[25] B. Heeg, Fast algorithm for computing non-isothermal crystallization kinetics, J. Non. Cryst. Solids. 438 (2016) 74-77. doi:10.1016/j.jnoncrysol.2015.10.014.

[26] R.P. Mooney, S. McFadden, Order verification of a Bridgman furnace front tracking model in steady state, Simul. Model. Pract. Theory. 48 (2014) 24-34.

[27] C.J. Roy, Review of code and solution verification procedures for computational simulation, J. Comput. Phys. 205 (2005) 131-156. doi:10.1016/j.jcp.2004.10.036.

[28] R.P. Mooney, S. McFadden, M. Rebow, D.J. Browne, A Front Tracking Model for Transient Solidification of Al-7wt\% Si in a Bridgman Furnace, Trans. Indian Inst. Met. 65 (2012) 527-530. doi:10.1007/s12666-012-0201-2.

[29] F.P. Incropera, D.P. Dewitt, T.L. Bergman, A.S. Lavine, Fundamentals of Heat and Mass Transfer, 6th ed., John Wiley \& Sons, New York, 2007. 